\title{
CAROTID ATHEROSCLEROSIS AND PERIPHERAL VASCULAR DISEASE IN TYPE 2 DIABETES MELLITUS PATIENTS WITH CORONARY ARTERY DISEASE
}

\author{
${ }^{1}$ Associate Professor, Department of Medicine, Grant Govt. Medical College, Mumbai. \\ ${ }^{2}$ Associate Professor, Department of Medicine, Indira Gandhi Medical College, Nagpur. \\ ${ }^{3}$ Assistant Professor, Department of Medicine, Grant Govt. Medical College, Mumbai. \\ ${ }^{4}$ Associate Professor, Department of Medicine, Grant Govt. Medical College, Mumbai. \\ ${ }^{5}$ Assistant Professor, Department of ENT, Grant Govt. Medical College, Mumbai. \\ ${ }^{6}$ Assistant Professor, Department of Medicine, Hi-Tech Hospital, Rourkela, Orissa.
}

Neetu Agarwal', Rajashree Khot², Sachin Jaybhaye ${ }^{3}$, Vinayak Sawardekar', Ramkumar Soni ${ }^{5}$, Chandan Bansal ${ }^{6}$

\begin{abstract}
BACKGROUND

Patients with Type 2 Diabetes Mellitus (DM) suffer from premature severe atherosclerosis and can have multivascular involvement.

Aims and Objectives- To determine the prevalence of Carotid Atherosclerosis (CA) and Peripheral Vascular Disease (PVD) in Type 2 DM patients with coronary artery disease. To correlate multivascular morbidity with risk factors.
\end{abstract}

\section{MATERIALS AND METHODS}

In cross-sectional hospital-based study, 120 consecutive patients of Type 2 DM with CAD underwent Doppler studies and prevalence of CA or PVD was determined as per IMT, plaques and luminal stenosis. Macrovascular multimorbidity defined as presence of CA or PVD or both along with CAD. They were assessed for risk factors. Patients were divided into 2 groups: Group ICAD alone, Group II- Multivascular morbidity. Comparisons were made using student ' $\mathrm{t}$ ' test and chi-square for univariate analysis and multivariate analysis done finally.

\section{RESULTS}

Mean age of patients was $56.17+7.8$ years with M:F = 1:1. Of 120 patients $71(59.1 \%)$ had CA (p=0.001), 40 (33.3\%) had PVD $(\mathrm{p}=0.732)$ and $28(23.3 \%)$ had both CA and PVD. Of 71 with CA 37 (52.11\%) had increased IMT, 34 (47.88\%) had plaques/luminal stenosis. Of 40 with PVD, 33 (82.5\%) had increased IMT, 7 (17.5\%) had plaques/stenosis. On univariate analysis male sex, age, duration of diabetes, hypertension, elevated fasting blood glucose and HbA1c, high LDL and low LDL were significantly associated with multivascular involvement. On multivariate analysis age, duration of diabetes, HbA1c were independent risk factors for multivascular involvement.

\section{CONCLUSION}

There is significantly high prevalence of macrovascular multimorbidity in Type 2 DM patients with CAD, more commonly in males. It is more with increasing age, Diabetes duration, Hypertension, uncontrolled DM and dyslipidaemia.

\section{KEYWORDS}

Type 2 DM, Coronary Artery Disease, Macrovascular Multimorbidity (CA and PVD).

HOW TO CITE THIS ARTICLE: Agarwal N, Khot R, Jaybhaye S, et al. Carotid atherosclerosis and peripheral vascular disease in type 2 diabetes mellitus patients with coronary artery disease. J. Evolution Med. Dent. Sci. 2017;6 (41):3209-3213, DOI: $10.14260 /$ Jemds/2017/695

\section{BACKGROUND}

Diabetics are more prone to advanced atherosclerosis and its sequelae namely Coronary Artery Disease (CAD), cerebrovascular disease, aortic atherosclerosis and peripheral vascular disease. Coronary Angiography (CAG) has been considered as the gold standard for the assessment of the degree of coronary atherosclerosis. But angiographic assessment of the coronary arteries is expensive, needs tertiary care hospitals and expertise and is not without risk.

Financial or Other, Competing Interest: None.

Submission 03-04-2017, Peer Review 09-05-2017,

Acceptance 15-05-2017, Published 22-05-2017.

Corresponding Author:

Dr. Neetu Agarwal,

\#312 Darshana Apartments,

90 Feet Road, Near Campus Hotel,

Mulund East, Mumbai-400081.

E-mail: netagrawal@gmail.com

DOI: $10.14260 /$ jemds $/ 2017 / 695$
Since atherosclerosis is a generalised phenomenon and is more or less present equally in the coronary, cerebral and the carotid arteries; so ultrasonographic assessment of easily accessible arteries has been advocated as a surrogate marker for less accessible vessels, such as coronary and cerebral arterial systems.

Carotid IMT (CIMT) has been shown to be independently associated with CAD in Indian subjects.1,2 Therefore, the present study was planned to generate more data on this subject with the aim of measuring atherosclerotic changes in carotid arteries and in peripheral arteries in Type 2 Diabetes Mellitus (T2DM) with CAD and to correlate them with various known coronary risk factors.

\section{Aims and Objectives \\ Primary}

To determine the prevalence of carotid atherosclerosis and peripheral vascular disease by Doppler studies in patients of Type 2 diabetes mellitus with coronary artery disease. 


\section{Secondary}

To correlate the multivascular morbidity in T2DM patients with cardiovascular risk factors like age, smoking, lipid profile, hypertension, duration of diabetes, etc.

\section{MATERIALS AND METHODS}

This cross-sectional hospital-based study included 120 patients of Type 2 diabetes mellitus (newly detected or on treatment) with coronary artery disease as diagnosed by Electrocardiography (ECG), Treadmill Stress Test (TMT) or Coronary Angiography (CAG). Diagnosis of type 2 diabetes was made based on blood sugar fasting and post-meal according to WHO criteria. Diagnosis of coronary artery disease was confirmed by presence of any one of these criteria:

i) ST-T changes, suggestive of ischaemia with anginal chest pain.

ii) Old Myocardial Infarction (MI).

iii) Recent MI.

iv) Positive TMT.

v) CAD as confirmed by CAG.

Diagnosis of Carotid Atherosclerosis was diagnosed by Doppler done on Aloka 4000 Prosound machine by presence of any one or more of the following-

i) Increased Intima Media Thickness (IMT) $>0.8 \mathrm{~mm}$.

ii) Presence of plaque: fibrofatty or calcific.

iii) Presence of stenosis, i.e. > 50\% luminal narrowing.

Diagnosis of Peripheral Vascular Disease was diagnosed by Doppler by presence of any one or more of the following-

i) Increased IMT $>1 \mathrm{~cm}$.

ii) Presence of plaque.

iii) Presence of stenosis, i.e. luminal narrowing $>50 \%$.

Multivascular morbidity was defined as presence of carotid atherosclerosis or peripheral vascular disease or both along with coronary artery disease. Type I diabetes mellitus, patients with age $<31$ and $>65$ years and having other associated causes of PVD and carotid atherosclerosis (like Takayasu's arteritis, Aortoarteritis, etc.) were excluded from the study. Each patient underwent detailed clinical history, physical examination and relevant laboratory investigations. Patients were divided into 2 groups for comparison, i.e. those patients with coronary artery disease alone and those with multivascular morbidity. Statistical analysis of data as per protocol was performed.

\section{Statistical Analysis}

Patients were divided into 2 groups for comparison, i.e. those patients with coronary artery disease alone and those with multivascular morbidity. All values were expressed as mean \pm SD or as percentages. Statistical analysis was performed by using "SPSS - version 15" on personal computer. Statistical analysis included the usual descriptive and univariate analysis. Student ' $t$ ' test was used to compare continuous variables. For categorical variables, chi-square test was used and 95\% Confidence Interval (CI) along with ' $p$ ' value was calculated. A P value $<0.05$ was considered as statistically significant. In addition to usual descriptive and univariate analysis, multivariate analysis was also made.

\section{RESULTS}

In the present study, a total of 120 type 2 diabetes mellitus patients attending diabetes clinic/indoor cases were included. Majority of patients (47.5\%) were in age group 60 65 years. Mean age of patients was $56.17 \pm 7.88$ years and male: female ratio was $1: 1$. Out of the 120 patients, 37 i.e. $30.8 \%$ had normal carotid and peripheral arterial Doppler, while 71 patients (59.1\%) had carotid atherosclerosis along with Coronary Artery Disease (CAD). This was statistically significant $(\mathrm{p}=0.001)$ (Table 1$) ; 40$ patients $(33.3 \%)$ had peripheral arterial disease along with $C A D$, but this was statistically insignificant $(\mathrm{p}=0.732)$.

Out of 71 patients with carotid atherosclerosis, 37 (52.11\%) patients had increased Intima-Media Thickness. Mean Intima-Media Thickness was found to be $1.04 \mathrm{~mm} ; 30$ patients (42.25\%) had plaque, out of which 18 (25.35\%) had fibrofatty plaque and 12 (16.9\%) had fibrocalcific plaque; 4 patients $(5.63 \%)$ had stenosis with haemodynamic compromise. Out of 40 patients with peripheral vascular disease $5(12.5 \%)$ had atherosclerotic plaque, while 2 (5\%) patients had stenosis with haemodynamic compromise. Rest of the patients had diffuse atherosclerotic changes in the form of increased Intima-Media Thickness. The mean age in the group who had CAD alone was $53.05 \pm 9.64$ years, while in the group who had CAD, carotid atherosclerosis and PVD mean age was $59 \pm 5.75$ years. This difference in age was statistically significant $(\mathrm{p}<0.001)$. As the age increased, multivascular involvement increased. Single macrovascular involvement in the form of CAD alone was more frequent in female, i.e. $40 \%$ as compared to $21.7 \%$ in males. This difference was statistically significant $(p=0.03)$. However, multivascular involvement was more prevalent in males $78.33 \%$ as compared to $60 \%$ in females. This difference was also statistically significant $(\mathrm{p}=0.024)$. Mean duration of diabetes in patients with single macrovascular involvement, i.e. $\mathrm{CAD}$ alone was $3.22 \pm 4.3$ years, while in those with multivascular involvement was $6.45 \pm 5.25$ years. The difference was statistically significant $(p=0.001)$. Hence, as duration of diabetes increase, multivascular involvement increased (Table 2). Mean fasting blood sugar in the group with multivascular involvement was high compared to those with CAD alone $(p=0.012)$. Mean HDL was low and mean LDL was high in the group with multivascular involvement compared to those with CAD alone (P value 0.002 and < 0.001 , respectively). Amongst other risk factors, hypertension was found to be significantly associated in the group with multivascular involvement (Table 3).

\begin{tabular}{|c|c|c|}
\hline $\begin{array}{l}\text { Macrovascular } \\
\text { Involvement }\end{array}$ & No. of Patients & $P$ value \\
\hline CAD Alone & $37(30.8 \%)$ & \\
\hline $\mathrm{CAD}+\mathrm{CA}$ & $43(35.8 \%)$ & 0.001 \\
\hline CAD + PVD & $12(10 \%)$ & 0.732 \\
\hline $\mathrm{CAD}+\mathrm{CA}+\mathrm{PVD}$ & $28(23.3 \%)$ & 0.013 \\
\hline Total & 120 & \\
\hline \multicolumn{3}{|c|}{$\begin{array}{c}\text { Table 1. Macrovascular Multi-Morbidity } \\
\text { in Type } 2 \text { Diabetes Mellitus }\end{array}$} \\
\hline
\end{tabular}




\begin{tabular}{|c|c|c|c|c|}
\hline \multirow{2}{*}{$\begin{array}{c}\text { Duration of } \begin{array}{c}\text { MM } \\
\text { DYears) }\end{array} \\
\text { CAD Alone }\end{array}$} & \multicolumn{3}{|c|}{ Multivascular Morbidity } \\
\cline { 3 - 5 } & CAD + CA & CAD + PVD & $\begin{array}{c}\text { CAD + CA } \\
\text { + PVD }\end{array}$ \\
\hline $0-5$ & $30(42 \%)$ & $24(34 \%)$ & $7(10 \%)$ & $10(14 \%)$ \\
\hline $6-10$ & $4(12 \%)$ & $13(39 \%)$ & $4(12 \%)$ & $12(36 \%)$ \\
\hline $11-15$ & $2(17 \%)$ & $3(25 \%)$ & $1(8 \%)$ & $6(50 \%)$ \\
\hline$>15$ & $1(25 \%)$ & $3(75 \%)$ & - & - \\
\hline Mean & $3.22 \pm 4.3$ & \multicolumn{3}{|c|}{$6.45 \pm 5.25$} \\
\hline Total & $\mathbf{3 7}$ & $\mathbf{4 3}$ & $\mathbf{1 2}$ & $\mathbf{2 8}$ \\
\hline \multicolumn{5}{|c|}{ Table 2. Correlation of Duration of Diabetes and } \\
Multivascular Involvement \\
\hline
\end{tabular}

\begin{tabular}{|c|c|c|c|c|c|c|c|}
\hline \multicolumn{2}{|c|}{ Risk Factors } & $\begin{array}{l}\text { CAD } \\
\text { Alone }\end{array}$ & CA & PVD & $\begin{array}{c}\text { CAD + } \\
\text { CA + } \\
\text { PVD }\end{array}$ & Total & $\begin{array}{c}P \\
\text { value }\end{array}$ \\
\hline \multicolumn{2}{|c|}{ Hypertension } & $\begin{array}{c}28 \\
(33 \%)\end{array}$ & $\begin{array}{c}30 \\
(36 \%)\end{array}$ & $6(7 \%)$ & $\begin{array}{c}20 \\
(24 \%)\end{array}$ & 84 & 0.001 \\
\hline \multicolumn{2}{|c|}{ Smoking } & $\begin{array}{c}4 \\
(21 \%)\end{array}$ & $\begin{array}{c}6 \\
(32 \%)\end{array}$ & \begin{tabular}{|c|}
4 \\
$(21 \%)$
\end{tabular} & $\begin{array}{c}5 \\
(26 \%)\end{array}$ & 19 & 0.901 \\
\hline \multicolumn{2}{|c|}{ Alcohol } & 1 & 3 & 1 & 1 & 6 & .572 \\
\hline \multicolumn{2}{|c|}{ Dyslipidaemia } & $\begin{array}{c}24 \\
(29 \%)\end{array}$ & $\begin{array}{c}33 \\
(40 \%)\end{array}$ & $8(9 \%)$ & $\begin{array}{c}18 \\
(22 \%)\end{array}$ & 83 & 0.001 \\
\hline \multirow{3}{*}{$\begin{array}{l}\text { Family } \\
\text { History }\end{array}$} & DM & 1 & 3 & 1 & 1 & 6 & \multirow{3}{*}{0.446} \\
\hline & HT & - & 2 & 1 & - & 3 & \\
\hline & \begin{tabular}{|l|} 
CAD \\
\end{tabular} & 2 & 1 & 1 & - & 4 & \\
\hline \multicolumn{8}{|c|}{$\begin{array}{c}\text { Table 3. Risk Factors and Association } \\
\text { with Multivascular Morbidity }\end{array}$} \\
\hline
\end{tabular}

Multivariate regression analysis (Table 4) suggested that increasing age, increasing duration of diabetes and male sex had more prevalence of multivascular morbidity. Fasting blood sugar, hypertension and dyslipidaemia were not found to be independent predictors of multivascular morbidity, although they were significant risk factors on univariate analysis.

\begin{tabular}{|c|c|c|c|}
\hline Variable & $\begin{array}{c}\text { CAD Alone } \\
\text { (n= 37) }\end{array}$ & $\begin{array}{c}\text { Multivascular } \\
\text { Morbidity } \\
\text { (n= 83) }\end{array}$ & P value \\
\hline Age (mean) & $53.05 \pm 9.64$ & $58.16 \pm 6.55$ & 0.025 \\
\hline M:F & $1: 1.18$ & $1.3: 1$ & 0.009 \\
\hline Hypertension & 28 & 56 & 0.248 \\
\hline $\begin{array}{c}\text { Mean Duration } \\
\text { of DM }\end{array}$ & $3.22 \pm 1.3$ & $6.45 \pm 5.25$ & 0.015 \\
\hline Mean FBS & $141.13 \pm 26.76$ & $160.47 \pm 42.5$ & 0.144 \\
\hline Mean HbA1c & $7.62 \pm 0.64$ & $8.85 \pm 1.42$ & 0.011 \\
\hline Mean HDL & $39.92 \pm 4.71$ & $36.98 \pm 4.62$ & 0.791 \\
\hline Mean LDL & $119.47 \pm 34.94$ & $146.14 \pm 35.6$ & 0.248 \\
\hline \multicolumn{4}{|c|}{ Table 4. Multiple Regression Analysis } \\
\hline
\end{tabular}

\begin{tabular}{|c|c|c|c|c|c|c|}
\hline Variable & B (Beta Adjusted Odds) & S. E. (Std. Error) & Wald & df (Degree of Freedom) & Significance & Exp. \\
\hline Age & 0.038 & 0.030 & 4.990 & 1 & 0.025 & 1.070 \\
\hline Sex & 1.296 & 0.495 & 6.849 & 1 & 0.009 & 3.654 \\
\hline Duration of Diabetes & 0.148 & 0.061 & 5.883 & 1 & 0.015 & 1.160 \\
\hline FBS & 0.010 & 0.007 & 2.130 & 1 & 0.144 & 1.010 \\
\hline HDL & -0.17 & 0.51 & 0.118 & 1 & 0.731 & 0.983 \\
\hline LDL & 0.002 & 0.007 & 0.070 & 1 & 0.791 & 1.002 \\
\hline Hypertension & 0.607 & 0.525 & 1.336 & 1 & 0.248 & 1.834 \\
\hline
\end{tabular}

\section{DISCUSSION}

Patients with diabetes mellitus are at an increased risk of morbidity and mortality from macrovascular disease manifesting as Coronary Artery Disease (CAD), Cerebrovascular Accident (CVA) and Peripheral Vascular Disease (PVD). Increased frequency of dyslipidaemia, hyperglycaemia, obesity, hypertension and associated nephropathy may contribute to accelerated atherogenesis in diabetic patients. A non-invasive technique of assessing carotid atherosclerosis or peripheral arterial disease by 2D Doppler duplex scanning has generated considerable interest as a marker of atherosclerosis and in the prediction of clinical coronary events and coronary artery disease, especially in resource limited country like India. The present study is an example of evidence-based medicine in correlating multiple vascular beds, coronary, carotid and peripheral which share the same atherosclerotic risk factors. The primary aim of this study was to determine the prevalence of CA and PVD in type 2 DM patients who already had evidence of atherosclerosis in the form of coronary artery disease.

Similar to our study AK Agarwal, PK Gupta, et $\mathrm{al}^{3}$ showed that the mean carotid IMT was significantly higher $(p<0.0001)$ in Type 2 diabetics with CAD (Both overt and silent) than in those without CAD. Mudríková $\mathrm{T}$ et $\mathrm{al}^{4}$ also found significantly increased Intima-Media thickness of the distal common carotid artery in patients with coronary artery disease. Kasliwal RR et al $^{5}$ also concluded from their study that both the mean and maximum carotid IMT were significantly higher in CAD group as compared to the nonCAD group.

The study conducted by Sodhi HS, Shrestha SK, et al ${ }^{6}$ recommended that $\mathrm{ABI}$ as measured by sphygmomanometer be incorporated into routine cardiovascular screening and when found to be abnormal should be further confirmed by Doppler assessment of ABI and CCA IMT as surrogate markers of atherosclerotic vascular disease. In contrast to this the present study showed 33.3\% (40 patients) had peripheral arterial disease in association with CAD, which was statistically insignificant $(\mathrm{p}=0.732)$.

Prevalence of CA + PVD in CAD has not been determined in any study so far. Hence, we would like to report this fact, further substantiating the theory of accelerated atherogenesis in Type 2 diabetics leading to multivascular involvement. Thus, it can be said that multivascular involvement is more prevalent in Type 2 DM with CAD and that carotid atherosclerosis is more prevalent than peripheral vascular disease in diabetics with coronary artery disease. Few patients also have atherosclerotic involvement of all major vessels, i.e. carotid, femoral and coronaries. 
The correlation of increasing age with carotid atherosclerosis was comparable with study conducted by KP Paulose, ${ }^{7}$ who also showed a strong positive correlation with increasing age. Multivariate regression analysis proved that age and diabetes were the major risk factors for increased IMT.

Multivariate logistic regression analysis in this study had shown that the risk for carotid artery disease is 5 -fold in patients with diabetes of more than 15 years duration $(95 \%$ CI 2.0-17.1 $\mathrm{p}=0.0003$ ) as compared to those with less than 5 years duration. KP Paulose ${ }^{7}$ showed comparable results and found a strong positive correlation between the duration of the disease and the incidence of carotid atherosclerosis.

In the present study, mean fasting blood sugar in the patients with CAD alone was $141.13 \mathrm{mg} / \mathrm{dL}$, while it was $160.47 \mathrm{mg} / \mathrm{dL}$ in patients with multivascular morbidity, which was statistically significant. Study conducted by Martens FM, Van Der Graaf Y, et $\mathrm{al}^{8}$ also showed that from all the components of the metabolic syndrome only high blood pressure and high fasting glucose influenced the carotid artery stiffness.

In our study, high LDL and low HDL were significantly associated with multivascular morbidity in univariate analysis. However, on multivariate analysis, multivascular involvement in diabetics was found to be independent of dyslipidaemia. This is because various mechanisms of increased atherosclerosis apart from dyslipidaemia are proposed in diabetics. These include oxidative stress, toxic effect of hyperglycaemia, endothelial dysfunction, etc. Rituparna Maiti et $\mathrm{al}^{9}$ studied the concept of inflammation in diabetes-accelerated atherosclerosis and proposed inflammatory mechanisms coupled with dyslipidaemia in the process of atheroma formation in diabetics.

\section{CONCLUSION}

It was a cross-sectional study, carried out to determine the prevalence of carotid atherosclerosis and peripheral vascular disease by Doppler studies in patients of Type II diabetes mellitus with coronary artery disease and to correlate the multivascular morbidity in these patients with risk factors like age, smoking, lipid profile, hypertension, duration of diabetes, etc.

We concluded that-

1) 83 patients out of 120 had multivascular morbidity, which was statistically significant high prevalence of macrovascular multimorbidity in Type 2 DM patients with CAD.

2) Multivascular involvement was more prevalent in males, i.e. $78.33 \%$ as compared to $60 \%$ in females. This difference was statistically significant.

3) The mean age in the group who had CAD alone was $53.05 \pm 9.64$ years, while in the group who had multivascular morbidity mean age was $59 \pm 5.75$ years. This difference in age was statistically significant.

4) Mean duration of diabetes among patients with CAD alone was $3.22 \pm 4.3$ years. While mean duration of diabetes in patients with multivascular involvement was $6.45 \pm 5.25$ years. This difference was statistically significant.

5) Mean fasting blood sugar was $141.13 \pm 26.76 \mathrm{mg} / \mathrm{dL}$ and $160.47 \pm 42.5 \mathrm{mg} / \mathrm{dL}$ in patients with CAD alone and those with multivascular morbidity respectively. This difference was statistically significant. Mean post-meal sugar in patients with CAD alone and patients with multivascular morbidity was $216.49 \pm 58.84 \mathrm{mg} / \mathrm{dL}$ and $241.92 \pm 79.89 \mathrm{mg} / \mathrm{dL}$ respectively. The difference was found to be statistically insignificant.

6) Mean HDL in patients with CAD alone was $39.92 \pm 4.71$ $\mathrm{mg} / \mathrm{dL}$, while in those with multivascular morbidity was $36.98 \pm 4.62 \mathrm{mg} / \mathrm{dL}$. The difference was statistically significant.

7) On multiple logistic regression analysis, multivascular morbidity was significantly associated with age of the patient and duration of diabetes after adjustment for other risk factors like hypertension, dyslipidaemia and fasting blood sugar.

\section{Limitation of the Study}

Present study has not taken into consideration the long-term diabetes control in the form of glycated haemoglobin (HbA1C). Also, aortic stiffness (measured non-invasively by brachial-ankle pulse wave velocity) and renal artery involvement by atherosclerosis were not taken into consideration in the present study.

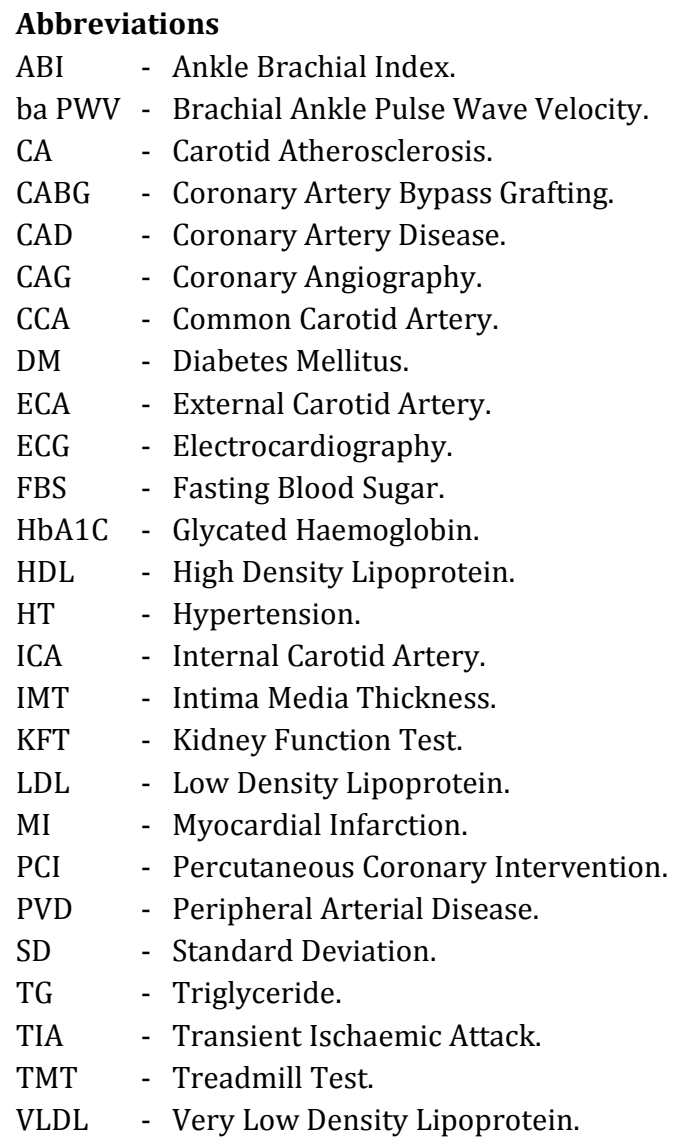

\section{REFERENCES}

[1] Jadhav UM, Kadam NN. Carotid intima-media thickness as an independent predictor of coronary artery disease. Indian Heart J 2001;53(4):458-62.

[2] Hansa G, Bhargava K, Bansal M, et al. Carotid intimamedia thickness and coronary artery disease: an Indian perspective. Asian Cardiovasc Thorac Ann 2003;11(3):217-21. 
[3] Agarwal AK, Gupta PK, Singla S, et al. Carotid intimomedial thickness in type 2 diabetic patients and its correlation with coronary risk factors. JAPI 2008;56:581-6.

[4] Mudríková T, Szabová E, Tkác I. Carotid intima-media thickness in relation to macrovascular disease in patients with type 2 diabetes mellitus. Wien Klin Wochenschr 2000;112(20):887-91.

[5] Kasliwal RR, Bansal M, Bhargava K, et al. Carotid intima-media thickness and brachial-ankle pulse wave velocity in patients with and without coronary artery disease. Indian Heart J 2004;56(2):117-22.

[6] Sodhi HS, Shrestha SK, Rauniyar R, et al. Prevalence of peripheral arterial disease by ankle-brachial index and its correlation with carotid intimal thickness and coronary risk factors in Nepalese population over the age of forty years. Kathmandu Univ Med J 2007;5(1):12-5.
[7] Paulose KP. Carotid artery disease in type 2 diabetes patients. International Journal of Diabetes In Developing Countries 2002;22:133-4.

[8] Martens FM, Graaf YVD, Dijk JM, et al. Carotid arterial stiffness is marginally higher in the metabolic syndrome and markedly higher in type 2 diabetes mellitus in patients with manifestations of arterial disease. Atherosclerosis 2008;197(2):646-53.

[9] Maiti R, Agrawal NK. Atherosclerosis in diabetes mellitus: role of inflammation. Indian Journal of Medical Sciences 2007;61(5):292-306. 